\title{
Sistem Pakar Diagnosis Troubleshooting Menggunakan Metode Forward Chaining Pada Perangkat Keras Komputer Berbasis Android
}

\author{
Sondang Sibuea ${ }^{1)}$, Yogi Pradiyatama Riyanto*)2) \\ ${ }^{122)}$ Program Studi Teknik Informatika, Universitas Mohammad Husni Thamrin \\ ${ }^{*}$ Correspondence author: yogi.apaya@gmail.com, DKI Jakarta, Indonesia
}

\begin{abstract}
Abstrak
Jika ada kerusakan perangkat keras atau hardware komputer saat ini biasanya tanpa pikir panjang seseorang akan membawanya kepada teknisi komputer, padahal tanpa disadari permasalahan tersebut dapat diatasi dengan mudah jika didampingi oleh seorang ahli atau pakar. Dengan perkembangan jaman yang serba digital dan dengan adanya Sistem Pakar memungkinkan seseorang dapat mengetahui permasalahan perangkat keras pada komputernya sendiri melalui androidnya dan dapat memperbaikinya sendiri tanpa harus membawanya ke teknisi komputer. Sistem Pakar adalah suatu sistem yang dirancang untuk dapat menirukan keahlian seorang pakar dalam menjawab pertanyaan dan memecahkan suatu masalah. Dengan adanya ahli komputer dalam android, merupakan wsalah satu perkembangan teknologi jaman ini. Dalam penelitian ini akan menggunakan metode identifikasi, yaitu penentuan hal-hal penting dari permasalahan yang akan analisis. Berdasarkan hal tersebut, maka dalam pembuatan aplikasi sistem pakar diagnosis troubleshooting pada perangkat keras komputer, user dapat mengetahui kendala yang terjadi dan akan diberikan saran serta masukan tentang apa yang harus dilakukan selanjutnya. Diharapkan aplikasi ini dapat dikembangkan perkembangan jaman.
\end{abstract}

Kata Kunci: Sistem Pakar, Andoid, Troubleshooting, Forward Chaining

\begin{abstract}
If there is damage to the hardware or computer hardware at this time usually without a second thought someone will take it to a computer technician, but without realizing that problem can be easily resolved if accompanied by an expert system or expert. With the development of the all-digital era and with the Expert System allows someone to find out the hardware problems on his own computer through Android and can fix it yourself without having to take it to a computer technician. Expert System is a system designed to be able to imitate the expertise of an expert in answering questions and solving a problem. The existence of computer experts in Android, is one of the technological developments of this era. In this study will use the identification method, namely the determination of the important things of the problem to be analyzed. Based on this, then in making an expert diagnosis system application troubleshooting on computer hardware, the user can find out the constraints that occur and will be given advice and input on what to do next. It is hoped that this application can be developed by the times.
\end{abstract}

Keywords: Expert System, Android, Troubleshooting, Forward Chaining

\section{PENDAHULUAN}

Perkembangan komputer dari masa ke masa membuat lebih banyak manusia menggunakannya karena penawaran tools atau perangkat yang cukup mudah dan sangat membantu dalam mengerjakan suatu pekerjaan. Namun ada kalanya perangkat keras pada komputer yang digunakan manusia tersebut mengalami permasalahan. Hal tersebut wajar terjadi karena komputer juga bisa usang jika terus menerus dipergunakan tanpa ada pemeliharaan yang baik. 
Hardware atau disebut Perangkat Keras merupakan bagian yang sangat penting dalam Personal Computer, karena merupakan piranti untuk melakukan pengoperasian komputer. Perangkat Keras merupakan benda yang bisa disentuh, maka harus diperhatikan secara khusus terutama dalam hal perawatan agar dalam melakukan pengoperasiannya dapat berjalan dengan baik. Namun tetap saja tidak bisa terhindar dari kendala-kendala yang sering terjadi.

Sebagian mungkin hanya sebatas bisa mengoperasikan komputer ala kadarnya saja, jika ada permasalahan perangkat keras komputer yang cukup mudah untuk diperbaiki secara mandiri namun justru malah membawanya ke teknisi komputer yang akan menimbulkan biaya yang cukup banyak, bahkan terkadang terkena penipuan.

Salah satu bagian dari kecerdasan buatan atau Artificial Intelligence yang akhir-akhir ini mengalami perkembangan pesat adalah Sistem Pakar (expert system), yaitu suatu sistem yang dirancang untuk dapat menirukan keahlian seorang pakar dalam menjawab pertanyaan dan memecahkan suatu masalah. Sistem pakar (expert system) adalah perangkat lunak komputer yang berkemampuan menyimpan pengetahuan dan aturan dari domain pakar yang khusus. Fungsi yang utama perangkat lunak ini adalah untuk memindahkan secara efektif kumpulan pengetahuan dari pakar kepada mereka yang bukan pakar. Sistem Pakar akan memberikan pemecahan suatu masalah ketika pemakai melakukan konsultasi atau dialog kepada sistem atau program komputer. Dengan bantuan sistem pakar, seseorang yang bukan pakar atau ahli dapat menjawab pertanyaan, menyelesaikan masalah, serta mengambil keputusan yang biasanya dilakukan oleh seorang pakar.

Menurut Siswanto (2010) dalam B. Herawan Hayadi (2016:2) "Sistem pakar suatu cabang dari Artificial Intellegence yang cukup tua karena sistem ini mulai dikembangkan pada tahun 1960. Sistem pakar adalah program Artificial Intellegence dengan basis pengetahuan (Knowledge Base) yang diperoleh dari pengalaman atau pengetahuan pakar atau ahli dalam memecahkan persoalan pada bidang tertentu dan didukung oleh mesin Interensi/Inference Engine yang melakukan penalaran atau pelacakan terhadap sesuatu atau fakta-fakta dan aturan.

Sistem Pakar dapat mengaplikasikan atau menuangkan keahlian seorang teknisi atau seorang pakar dalam bidang komputer. Dengan begitu tidak usah susah-susah mendatangi langsung seorang teknisi atau pakar untuk melakukan troubleshooting. Pencarian solusi ataupun diagnosa kerusakan dapat dilakukan dengan cepat dan mudah.

Tanpa disadari kebanyakan Sistem Pakar menyelesaikan permasalahan pada komputer menggunakan aplikasi yang hanya bisa akses melalui Personal Computer saja, padahal komputer yang digunakan-pun bisa sedang mengalami kendala sehingga tidak bisa 
digunakan. Kelebihan dari Sistem Pakar ini yaitu berbasis android yang pada saat ini sudah bayak digunakan pada Handphone. Dengan adanya aplikasi ini diharapkan dapat membantu pengguna dalam menyelesaikan kendala pada komputernya.

\section{METODE}

Metode pengembangan Sistem Pakar terdiri dari 6 (enam) poin, yaitu :

\section{Identifikasi}

Tahapan ini merupakan penentuan hal-hal penting yang merupakan permasalahan utama. Tahapan ini merupakan tahapan untuk mengkaji dan membatasi masalah yang akan di implementasikan dalam sistem. Setiap masalah yang di implementasikan harus dicarikan solusi. Perlu diidentifikasi fasilitas yang akan di kembangkan, penentuan jenis bahasa pemrograman dan tujuan yang ingin dicapai dari proses pengembangan tersebut. Apabila proses identifikasi masalah dilakukan dengan benar maka akan dicapai hasil optimal.

\section{Konseptualisasi}

Hasil identifikasi masalah di konseptualisasikan dalam bentuk relasi antar data, hubungan antar pengetahuan dan konsep-konsep penting dan ideal yang akan diterapkan dalam sistem. Konseptualisasi juga menganalisis data-data penting yang harus didalami bersama dengan pakar di bidang dipermasalahan tersebut.

\section{Formalisasi}

Apabila tahap konseptualisasi telah selesai di lakukan, maka dilanjutkan formalisasi konsep-konsep tersebut. Konsep diimplementasikan secara formal, misalnya memberikan kategori sistem yang akan dibangun, mempertimbangkan beberapa faktor pengambilan keputusan seperti keahlian manusia, kesulitan dan tingkat kesulitan yang mungkin terjadi, dokumentasi kerja, dan sebagainya.

\section{Implementasi}

Apabila pengetahuan sudah diformalisasikan secara lengkap, maka tahap implementasi dapat dimulai dengan membuat garis besar implementasi. Kemudian memecahkan implementasi ke dalam modul-modul. Untuk memudahkan maka harus diidentifikasikan:

a. Apa saja yang menjadi inputannya.

b. Bagaimana prosesnya digambarkan dalam bagan alur dan basis aturannya.

c. Bagaimana output atau hasil dan kesimpulannya.

\section{Evaluasi}

Sistim pakar yang selesai di bangun, perlu untuk dievaluasi untuk menguji dan menemukan kesalahan. Hal ini merupakan hal yang umum dilakukan karena suatu 
sistem belum tentu sempurna setelah selesai pembuatannya, sehingga proses evaluasi diperlukan untuk penyempurnaanya.

6. Pengembangan Sistem

Pengembangan sistem diperlukan sehingga sistem yang dibangun tidak menjadi usang dan investasi sistem tidak sia-sia. Hal pengembangan sistem yang paling berguna adalah proses dokumentasi sistem di mana didalamnya tersimpan semua hal penting yang dapat menjadi tolak ukur pengembangan sistem di masa mendatang, termasuk didalamnya adalah kamus pengetahuan yang digunakan.

Troubleshooting pada Perangkat Keras Komputer yang akan dibahas terbagi menjadi dua bagian, yaitu kerusakan yang menyebabkan komputer tidak bisa dinyalakan dan kerusakan yang dapat dideteksi komputer setelah komputer menyala.

1. Kerusakan perangkat keras yang menyebabkan komputer tidak bisa dinyalakan yaitu:
a. Kerusakan pada Monitor.
b. Kerusakan pada Processor.
c. Kerusakan pada Power Supply.
d. Kerusakan pada Motherboard

2. Kerusakan perangkat keras yang dapat dideteksi komputer saat menyala yaitu:
a. Kerusakan pada Harddisk.
b. Kerusakan pada Mouse.
c. Kerusakan pada Keyboard.
d. Kerusakan pada Speaker.
e. Kendala Blue Screen karena komputer terlalu panas.
f. Kerusakan pada Random Access Memory.
g. Kerusakan pada Memory Video Card.

Menurut Sutojo dkk. (2011) Ada dua teknik penalaran (inference) yaitu sebagai berikut :

1. Forward Chaining (Pelacakan ke depan)

Teknik ini memulai pencarian dengan fakta yang diketahui untuk menguji kebenaran hipotesa, kemudian mencocokkan fakta tersebut dengan bagian IF dari rule $I F-T H E N$. Teknik ini cocok digunakan untuk menangani masalah peramalan (prognosis) dan pengendalian (controlling).

\section{Backward Chaining (Pelacakan ke belakang)}

Teknik ini memulai pencarian dari kesimpulan (goal) dengan mencari sekumpulan hipotesa-hipotesa yang mendukung menuju fakta-fakta yang mendukung sekumpulan hipotesa tersebut. 
Metode Forward Chaining adalah metode pencarian atau teknik pelacakan ke depan yang dimulai dengan informasi yang ada dan penggabungan rule untuk menghasilkan suatu kesimpulan atau tujuan. (Russel S,Norvig P, 2003). Pelacakan maju ini sangat baik jika bekerja dengan permasalahan yang dimulai dengan rekaman informasi awal dan ingin dicapai penyelesaian akhir, karena seluruh proses akan dikerjakan secara berurutan maju. Forward chaining merupakan metode inferensi yang melakukan penalaran dari suatu masalah kepada solusinya. Jika klausa premis sesuai dengan situasi (bernilai TRUE), maka proses akan menyatakan konklusi. Forward chaining adalah data driven karena inferensi dimulai dengan informasi yang tersedia dan baru konklusi diperoleh. Jika suatu aplikasi menghasilkan tree yang lebar dan tidak dalam, maka gunakan forward chaining.

\section{HASIL DAN PEMBAHASAN}

Berikut diagnosis kerusakan perangkat keras komputer yang dibuat:

a. Kaidah 1

Jika tombol power pada CPU menyala namun monitor mati lalu kabel power monitor dan kabel VGA sudah dipastikan dalam kondisi baik dan terpasang dengan benar, maka kerusakan ada pada Monitor.

b. Kaidah 2

Jika tombol power pada CPU menyala dan tombol power monitor menyala lalu monitor tidak merespon apapun (blank screen), maka kerusakan ada pada Processor.

c. Kaidah 3

Jika tombol power CPU mati sementara tombol power menyala lalu kabel power pada CPU terpasang dengan benar lalu Tombol ON/OFF pada Power Supply sudah dalam keadaan $O N$ namun masih tidak menyala, maka kerusakan ada pada Power Supply.

\section{d. Kaidah 4}

Jika tombol power pada CPU mati sementara tombol power monitor menyala lalu kabel power pada CPU sudah terpasang dengan benar lalu tombol ON/OFF pada Power Supply dalam keadaan $O N$ dan menyala, maka kerusakan ada pada Motherboard.

e. Kaidah 5

Jika saat komputer melakukan booting kemudian ada tulisan "Detecting IDE driver" dan tidak merespon apapun lagi lalu kabel pada Harddisk yang terpasang diganti dengan kabel yang lain tetap tidak bisa merespon lalu kabel pada Harddisk sudah dipastikan dalam kondisi baik namun tetap tidak merespon, maka kerusakan ada pada Harddisk. 


\section{f. Kaidah 6}

Jika saat komputer menyala namun perangkat mouse tidak berfungsi lalu sudah dipastikan kabel pada mouse terpasang dengan benar pada komputer namun tidak bisa menyalah maka kerusakan ada pada Mouse.

\section{g. Kaidah 7}

Jika saat komputer dinyalakan tidak ada respon dari keyboard lalu kabel pada perangkat keyboard sudah dipastikan terhubung dengan baik dengan komputer namun tidak menunjukan respon apapun, maka kerusakan ada pada Keyboard.

h. Kaidah 8

Jika kabel penghubung komputer dengan speaker sudah dipastikan dengan benar pemasangannya lalu sudah dilakukan penggantian kabel penghubung dengan yang baru namun tidak meresepon lalu driver speaker sudah dipastikan sudah terinstal pada komputer namun tetap tidak merespon apapun maka kerusakan ada pada Speaker.

\section{i. Kaidah 9}

Jika muncul blue screen pada komputer yang berkodekan "Machine_Check_Exeption", maka komputer yang digunakan sudah terlalu panas.

j. Kaidah 10

Jika muncul blue screen pada komputer yang berkodekan "Pen_List_Corrupt", maka ada kerusakan pada Random Access Memory atau RAM.

k. Kaidah 11

Jika muncul blue screen pada komputer yang berkodekan "Page_Fault_In_Nonpaged", maka ada kerusakan pada Memory Video Card.

Gambar 1 menunjukkan gambaran pohon pelacakan dari modul konsultasi pada aplikasi sistem pakar diagnosis kerusakan pada perangkat keras komputer. 


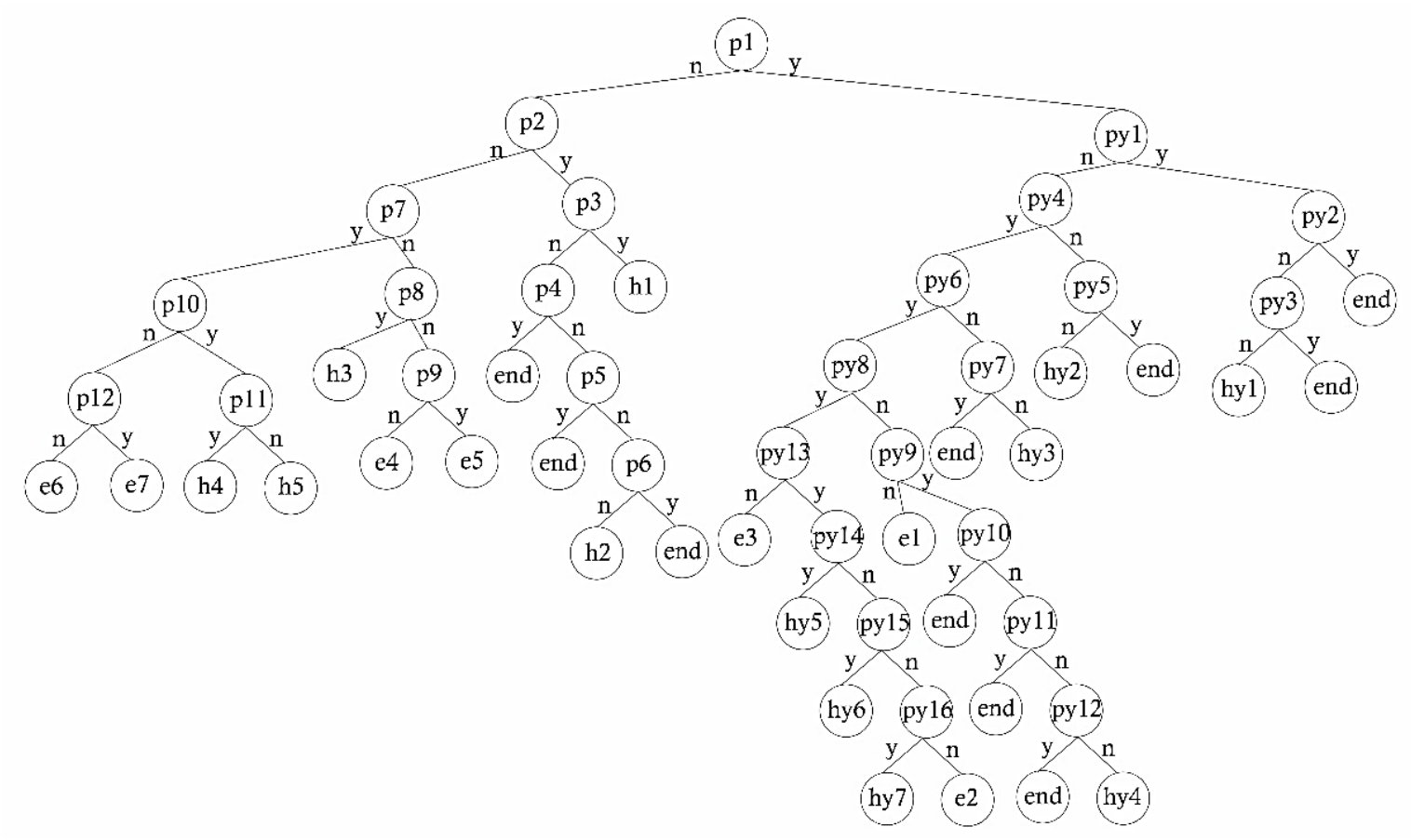

Gambar 1. Pohon Pelacakan

Pada tampilan lembar menu utama terdapat 5 jenis button, yaitu diantaranya adalah button konsultasi, button bantuan, button saran, button tentang dan button exit. Berikut merupakan tampilan serta program lembar menu utama dalam aplikasi.

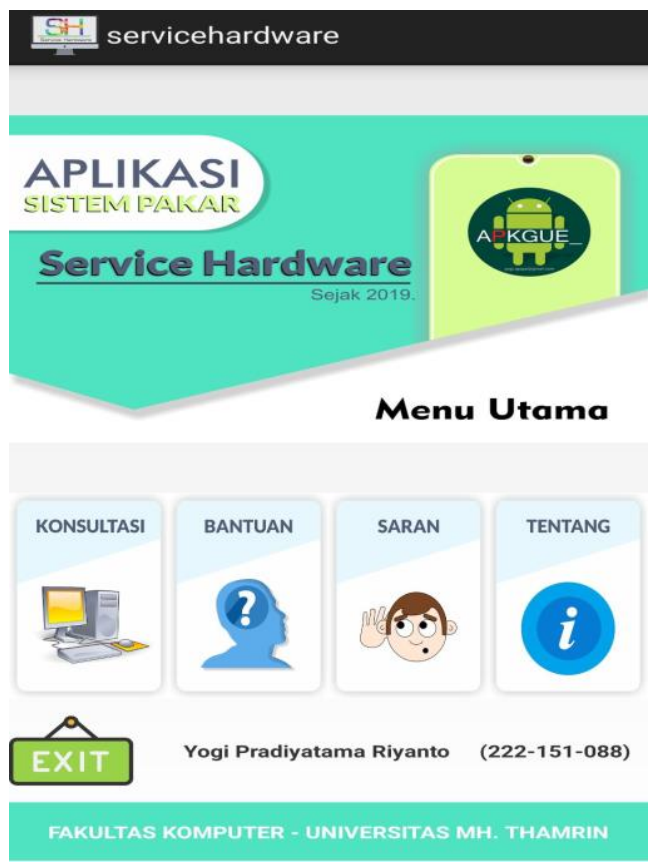

Gambar 2. Tampilan menu utama

Pada tampilan lembar konsultasi terdapat 3 jenis button, yaitu diantaranya adalah button back, button yes dan button no. Berikut merupakan tampilan dari salah satu layout konsultasi dengan nama file "p1". 


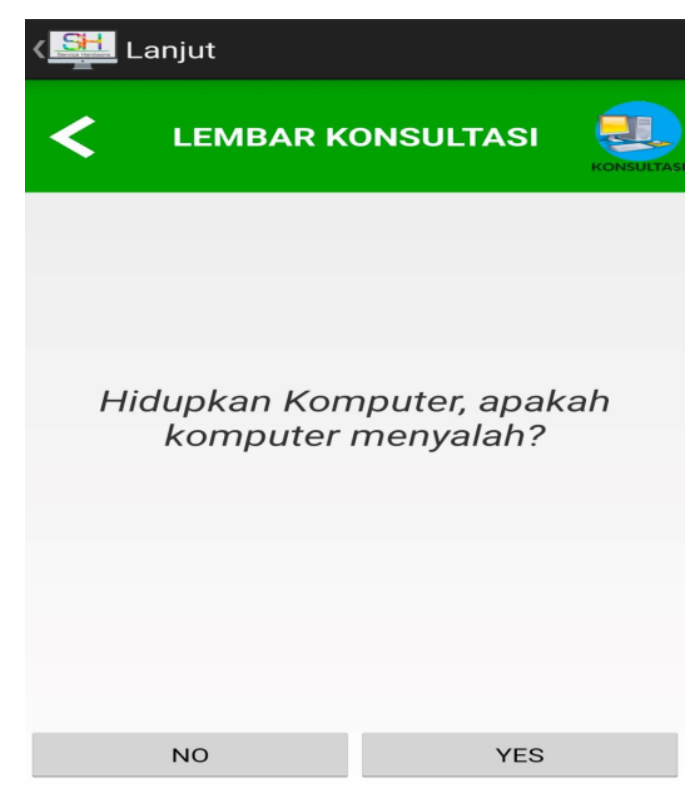

Gambar 3. Tampilan lembar konsultasi

Tampilan penemuan masalah merupakan sebuah halaman pada aplikasi service hardware yang didalamnya terdapat 2 buah button, yaitu button home dan button learning. Pada tampilan ini user akan diberikan pilihan untuk kembali kepada menu utama atau mempelajari masalah yang sudah ditemukan. Gambar 4 merupakan tampilan dari salah satu tampilan penemuan masalah dengan kode h1.xml

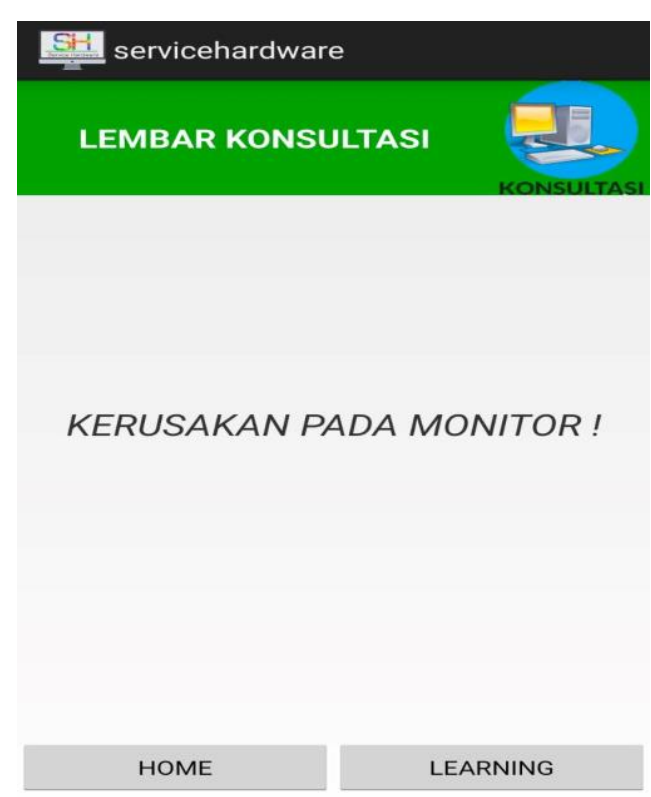

Gambar 4. Tampilan layout penemuan masalah

Pada tampilan pembelajaran menampilkan sebuah solusi kepada user dalam menindaklanjuti kendala yang ada pada perangkat keras komputer sesuai dengan kesimpulan dari hasil analisa aplikasi service hardware. Dalam tampilan pembelajaran hanya memiliki 1 button yaitu button home yang membawa user pada menu utama. Gambar 5 menunjukan tampilan dari halaman pembelajaran. 


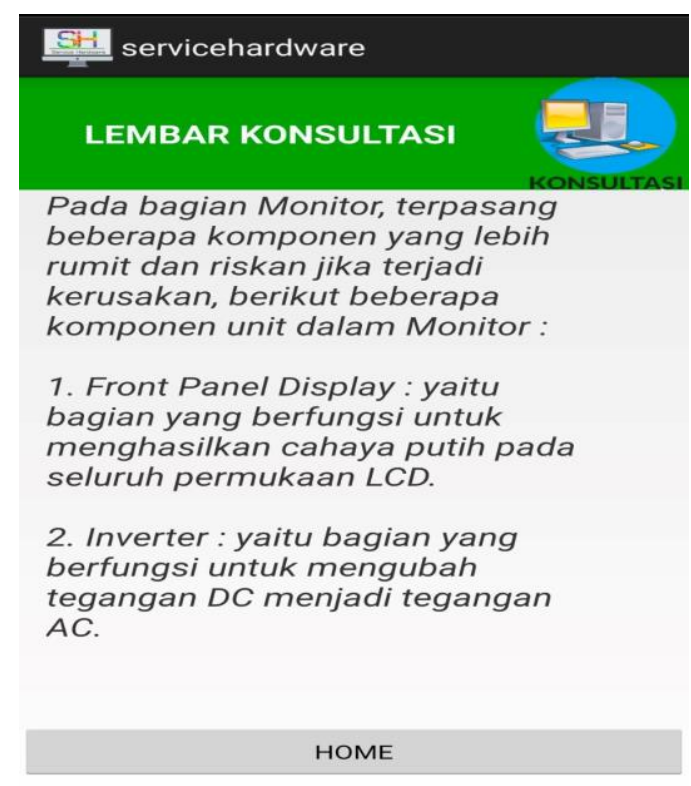

Gambar 5. Tampilan layout pembelajaran

\section{KESIMPULAN DAN REKOMENDASI}

Kesimpulan yang dapat diambil adalah, aplikasi sistem pakar diagnosis troubleshooting pada perangkat keras komputer dirancang sedemikian rupa agar memudahkan user atau pengguna aplikasi tersebut dalam memecahkan masalah ketika terjadi kendala atau kerusakan pada perangkat keras komputer dengan menggunakan smartphone android. Dengan menggunakan aplikasi sistem pakar ini dapat mengefisienkan waktu karena user yang menggunakan aplikasi ini seolah olah sedang berbincang dengan pakarnya. Dengan menggunakan android sebagai basis utama dalam pembuatan sistem pakar ini maka akan mempermudah user dalam mencari kesimpulan dalam kendala yang dihadapi.

Direkomendasikan bahwa, tampilan layout maupun isi konten yang disimpan perlu lebih diperbanyak lagi. Juga direkomendasikan bahwa kedepannya sistem pakar ini bisa menyelesaikan masalah perangkat lunak (software).

\section{REFERENSI}

Wibowo, Seno. 2014. Pengenalan, Permasalahan dan Penanganan Hardware Komputer. Yogyakarta : CV. ANDI OFFSET (Penerbit ANDI).

S, Rosa A. 2018. Rekayasa Perangkat Lunak Terstruktur dan Berorientasi Objek. Bandung : Informatika Bandung.

Andriani, Anik. 2016. Pemrograman Sistem Pakar Konsep Dasar dan Aplikasinya menggunakan Visual Basic 6. Yogyakarta : MediaKom. 
Waloeya, Yuhan Jati. 2011. Hardware PC Panduan Komplit Tanpa Pake Sulit. Yogyakarta : CV. ANDI OFFSET (Penerbit ANDI).

Komputerdia, “Android Studio VS Eclipse, Manakah yang paling unggul?”, Diakses pada 18 November 2017. https://www.komputerdia.com/2017/11/android-studio-vseclipse-new-updates.html

GudangLinux Shop. "SDK (Software Development Kit)". Diakses pada 21 Juni 2018. http://gudanglinux.com/glossary/sdk-software-development-kit/

DosenIT.com. "10 Kelebihan dan Kekurangan CorelDraw bagi pengguna". https://dosenit.com/kuliah-it/desain/kelebihan-dan-kekurangan-corel-draw 